\title{
Compliance, tolerability and safety of two antioxidant-rich diets: a randomised controlled trial in male smokers
}

Anette Karlsen ${ }^{1}$, Mette Svendsen ${ }^{2}$, Ingebjørg Seljeflot ${ }^{3}$, Mary-Ann Sommernes ${ }^{2}$, Joseph Sexton ${ }^{4}$, Asgeir Brevik ${ }^{1}$, Iris Erlund ${ }^{5}$, Mauro Serafini ${ }^{6}$, Nasser Bastani ${ }^{1}$, Siv Fagertun Remberg ${ }^{7}$, Grethe I. Borge ${ }^{8}$, Monica Hauger Carlsen ${ }^{1}$, Siv Kjølsrud Bøhn ${ }^{1}$, Mari C. Myhrstad ${ }^{1}$, Lars O. Dragsted ${ }^{9}$, Asim K. Duttaroy ${ }^{1}$, Karin Haffner ${ }^{7} \dagger$, Petter Laake ${ }^{4}$, Christan A. Drevon ${ }^{1}$, Harald Arnesen ${ }^{3}$, Andrew Collins ${ }^{1}$, Serena Tonstad ${ }^{2}$ and Rune Blomhoff ${ }^{1 *}$

${ }^{1}$ Department of Nutrition, Faculty of Medicine, Institute of Basic Medical Sciences, University of Oslo, PO Box 1046, Blindern, 0316 Oslo, Norway

${ }^{2}$ Department of Preventive Cardiology, Oslo University Hospital Ulleval, Oslo, Norway

${ }^{3}$ Department of Cardiology, Center for Clinical Heart Research, Oslo University Hospital Ulleval, Oslo, Norway

${ }^{4}$ Department of Biostatistics, Institute of Basic Medical Sciences, University of Oslo, Oslo, Norway

${ }^{5}$ Department of Chronic Disease Prevention, National Institute for Health and Welfare, Helsinki, Finland

${ }^{6}$ Unit of Human Nutrition, Antioxidant Research Laboratory, INRAN, Rome, Italy

${ }^{7}$ Department of Plant and Environmental Sciences, Norwegian University of Life Sciences, Ås, Norway

${ }^{8}$ Nofima Mat AS, Norwegian Institute of Food, Fisheries and Aquaculture Research, As, Norway

${ }^{9}$ Department of Human Nutrition, Faculty of Life Sciences, University of Copenhagen, Copenhagen, Denmark

(Received 27 April 2010 - Revised 15 December 2010 - Accepted 20 December 2010 - First published online 12 May 2011)

\section{Abstract}

It has been suggested that antioxidants attenuate oxidative stress and prevent oxidative stress-related diseases. Paradoxically, randomised controlled trials (RCT) using pharmacological doses of antioxidant supplements have demonstrated harmful effects in smokers. The aim of the present study was to test the compliance, tolerability and safety of two food-based antioxidant-rich diets in smokers. One of the diets provided antioxidants at levels similar to that used in RCT using supplements which previously have generated harmful effects. The present study followed a randomised, parallel-arm dietary intervention for 8 weeks $(n$ 102) in male smokers (age $\geq 45$ years). Participants were randomised to either antioxidant-rich diet, kiwi fruit or control groups. The antioxidant-rich foods provided about $300 \mathrm{mmol}$ antioxidants/week from a wide range of plant-based food items. The kiwi fruit group consumed three kiwi fruits/d. Compliance to both diets was good. Only mild, undesirable events were reported by a minority of the participants. The safety of both diets was demonstrated as no potentially harmful or pro-oxidative effects were observed. In the antioxidant-rich diet group, the mean intake of antioxidants increased from $30 \mathrm{mmol} / \mathrm{d}$ at baseline to $62 \mathrm{mmol} / \mathrm{d}$ during the intervention. In conclusion, we have demonstrated that male smokers can comply with two food-based antioxidant-rich diets. Furthermore, the present study is the first to demonstrate the tolerability and safety of dietary antioxidants at levels similar to dosages provided in RCT using supplements. Such diets may be useful in future studies investigating whether dietary antioxidants may reduce oxidative stress and related diseases.

\section{Key words: Dietary antioxidants: Plasma antioxidants: Oxidative stress: Antioxidant network}

Oxidative stress is involved in the development of numerous diseases, including CVD and cancer $^{(1-3)}$. It has been suggested that antioxidants may attenuate oxidative stress and thereby inhibit the development of oxidative stressrelated diseases. The majority of epidemiological cohort and case-control studies studying associations between dietary antioxidants, or the serum concentration of antioxidants, and the incidence of oxidative stress-related diseases have been supportive of this hypothesis ${ }^{(4-8)}$. Thus, the second expert report from the World Cancer Research Fund and the American Institute of Cancer Research concluded that intake of foods containing specific antioxidant compounds such as

Abbreviations: FRAP, ferric-reducing/antioxidant power; ORAC, oxygen radical absorbance capacity; RCT, randomised controlled trial.

*Corresponding author: R. Blomhoff, fax +47 228513 41, email rune.blomhoff@medisin.uio.no

† Deceased. 
carotenoids, vitamin $\mathrm{C}$ and vitamin $\mathrm{E}$ probably reduces the risk of several types of cancer ${ }^{(9)}$. In contrast to these observations, most randomised controlled trials (RCT) using high doses of antioxidant compounds in supplements $(\beta$-carotene, vitamin $\mathrm{C}$ and vitamin $\mathrm{E}$ ) have not been supportive. Although some of these studies have shown beneficial effects, several studies have demonstrated no or even harmful effects, especially in smokers ${ }^{(10,11)}$. A recent meta-analysis investigating all-cause mortality in RCT using antioxidant supplements concluded that supplementation was dose-dependently associated with an increased risk of death ${ }^{(12)}$. Thus, although fruits and vegetables containing a large number of various antioxidants seem to be beneficial, supplements containing one or a few antioxidant compounds in pharmacological doses seem to have no or even harmful effects.

To study the possible preventive role of dietary antioxidants in oxidative stress-related diseases, we measured the total antioxidant content of more than 3500 foods ${ }^{(13-15)}$. In the present RCT, we used a comprehensive combination of antioxidantrich foods (such as berries, nuts, spices, fruits and vegetables) providing dietary antioxidants at levels that are similar to that only previously tested using supplements ${ }^{(16)}$. In the second intervention group, kiwi fruits, which are a rich source of vitamin C, were provided.

The primary aim of the present RCT was to test the compliance and tolerability of two food-based antioxidant interventions. Furthermore, as one of the interventions provided dietary antioxidants at levels similar to those previously administered in RCT using supplements, in which adverse effects among smokers have been indicated, the safety of these diets was evaluated. To our knowledge, no human intervention study has previously investigated the effects of similar amounts of total antioxidants provided by food sources alone.

\section{Subjects and methods}

\section{Subjects and sample size}

The participants were recruited via advertisement in a local newspaper. The inclusion criteria were men between 45 and 75 years, smoking at least five cigarettes/d and a stable weight range $( \pm 4 \mathrm{~kg}$ in the previous 3 months) and BMI $<35 \mathrm{~kg} / \mathrm{m}^{2}$ (for the last 6 months). The exclusion criteria were any history of symptomatic CVD (myocardial infarction, angina pectoris, coronary artery bypass graft surgery, percutaneous coronary intervention, congestive heart failure and heart failure classified according to the New York Heart Association grades III and IV), diabetes mellitus (type 1 or type 2) or other significant clinical disorders, including cancer and gastrointestinal diseases. Individuals following a vegetarian or near-vegetarian diet or having allergy to experimental foods were also excluded. Moreover, subjects with a history of serious or unstable medical or psychiatric disorder, current use of, or in need of, lipid-lowering drug treatment, aspirin or non-steroidal anti-inflammatory drugs, nutritional supplements or herbs for weight loss within the 4 weeks before inclusion, or participating in a drug trial during the last $30 \mathrm{~d}$ were not included. Sample size was determined using literature values and results from previous studies on expected effects $^{(17,18)}$. In the absence of background data on other endpoints, plasma antioxidant variables were used as primary endpoints for sample size calculations.

\section{Study design and intervention}

The study followed a randomised, parallel design with an 8week intervention period. A 4-week run-in period was included before randomisation. During the run-in and intervention periods, the participants were instructed to avoid any single vitamins or antioxidant supplementation and pain or cold remedies containing aspirin or aspirin-like drugs. As coffee is the major contributor of intake of dietary antioxidants in Norway, intake was limited to three cups/d. Furthermore, all participants were instructed to limit their use of berries, nuts, pomegranates, tomatoes, kiwi fruit and tea during the run-in and intervention periods.

After the run-in period, subjects were randomly assigned to one of the three groups: antioxidant-rich diet group, kiwi fruit group or control group. Randomisation was performed in blocks of twelve, with group allocation provided in presealed, numbered envelopes.

Subjects were provided with relevant food items at weekly follow-ups. For the antioxidant-rich diet group, the weekly amounts and the respective antioxidant content of the different food items are presented in Table 1. In total, the antioxidant-rich foods provided $300 \mathrm{mmol}$ antioxidants/week, as estimated by the ferric-reducing/antioxidant power (FRAP) assay (Table 1$)^{(13-15)}$, in which the amounts of total antioxidants are estimated based on the substance's ability to reduce $\mathrm{Fe}^{3+}$. The antioxidant-rich diet included green tea, juice of rose hips, orange, apple and carrot, juice of cranberries, raspberries and grapes, juice of black chokeberry, bilberries, grapes and cherries, bilberry juice, unsweetened bilberry jam, bilberries, blackberries, strawberries, raspberries, pomegranates, dark blue table grapes, Brussel sprouts, broccoli, red cabbage, kale, blue potatoes, tomatoes, dark chocolate (70\% cocoa), pecan nuts, sunflower seeds and walnuts. Extra virgin olive oil, rosemary, thyme and oregano were provided once at the start of the intervention period. The weekly amounts that were administered were, as far as possible, based on practical issues, i.e. size of container, suggested portion sizes (i.e. $100 \mathrm{~g}$ for fruit and vegetables) and taste (for nuts and seeds baked in bread). If not otherwise specified, all berries, fruits and vegetables were purchased from Odd Langdalen Frukt \& Grønnsaker Engros AS (Oslo, Norway). To increase the palatability of the diet, the sunflower seeds and walnuts were used as ingredients in bread.

Participants in the kiwi fruit group consumed three kiwi fruits/d (Actinidia deliciosa; Odd Langdalen Frukt \& Grønnsaker Engros AS). Weekly amounts were provided at follow-ups. Participants in the control group were advised to follow their habitual diet during the 8-week period, and were monitored at biweekly follow-ups.

Participants were included between March 2004 and March 2005. The Easter holiday, summer vacation and Christmas holiday were avoided to prevent possible confounding by 
Table 1. Antioxidant-rich food items provided to the antioxidant-rich diet group during the intervention period

\begin{tabular}{|c|c|c|c|}
\hline Food item & Manufacturer & Provided weekly & $\begin{array}{l}\text { Total antioxidants } \\
(\mathrm{mmol} / \text { week })\end{array}$ \\
\hline Green Java Tea & Twinings (London, UK) & Seven tea bags & $20 \cdot 86$ \\
\hline $\begin{array}{l}\text { Juice of rose hips, orange, apple } \\
\text { and carrot (Mana Yellow) }\end{array}$ & Tine BA (Oslo, Norway) & 1.66 litres & $42 \cdot 64$ \\
\hline $\begin{array}{l}\text { Juice of cranberries, raspberries } \\
\text { and grapes (Mana Red) }\end{array}$ & Tine BA (Oslo, Norway) & 1.66 litres & $10 \cdot 95$ \\
\hline $\begin{array}{l}\text { Juice of black chokeberry, bilberries, } \\
\text { grapes and cherries (Mana Blå) }\end{array}$ & Tine BA (Oslo, Norway) & 1.66 litres & $33 \cdot 18$ \\
\hline Bilberry juice (Vaccinium myrtillus) & Corona Safteri (Ranheim, Norway) & 0.66 litres & 54.73 \\
\hline Bilberry jam (V. myrtillus) & Heistad (Bergen, Norway) & $345 \mathrm{~g}$ & $10 \cdot 50$ \\
\hline Bilberries (V. myrtillus) & Odd Langdalen Engros (Oslo, Norway) & $200 \mathrm{~g}$ & $16 \cdot 24$ \\
\hline Blackberries (Rubus fruticosus) & Odd Langdalen Engros (Oslo, Norway) & $200 \mathrm{~g}$ & $9 \cdot 20$ \\
\hline Strawberries (Fragaria $\times$ ananassa) & Odd Langdalen Engros (Oslo, Norway) & $200 \mathrm{~g}$ & 4.26 \\
\hline Raspberries (Rubus idaeus) & Odd Langdalen Engros (Oslo, Norway) & $200 \mathrm{~g}$ & $5 \cdot 87$ \\
\hline Pomegranate (Punica granatum) & Odd Langdalen Engros (Oslo, Norway) & $200 \mathrm{~g}$ & 3.43 \\
\hline Dark blue grapes (Vitis sp.) & Odd Langdalen Engros (Oslo, Norway) & $200 \mathrm{~g}$ & $2 \cdot 23$ \\
\hline Brussel sprouts (Brassica oleracea var. gemmifera) & Odd Langdalen Engros (Oslo, Norway) & $200 \mathrm{~g}$ & 2.01 \\
\hline Broccoli (B. oleracea var. italica) & Odd Langdalen Engros (Oslo, Norway) & $200 \mathrm{~g}$ & 1.93 \\
\hline Red cabbage (oleracea var. capitata rubra) & Outdoor cultivar* & $200 \mathrm{~g}$ & $3 \cdot 82$ \\
\hline Kale (B. oleracea var. sabellica) & Outdoor cultivar* & $200 \mathrm{~g}$ & $4 \cdot 71$ \\
\hline Blue potatoes (Solanum tuberosum, 'Blue congo') & Odd Langdalen Engros (Oslo, Norway) & $150 \mathrm{~g}$ & 0.00 \\
\hline Tomatoes (Solanum lycopersicum) & Odd Langdalen Engros (Oslo, Norway) & $700 \mathrm{~g}$ & $2 \cdot 24$ \\
\hline Dark chocolate, $70 \%$ cocoa & Kraft Foods (Glenview, IL, USA) & $100 \mathrm{~g}$ & $11 \cdot 22$ \\
\hline Pecan nuts (Carya illinoinensis)† & Den lille nøttefrabrikken (Fredrikstad, Norway) & $100 \mathrm{~g}$ & 8.30 \\
\hline Sunflower seeds (Helianthus annuus) $\dagger$ & Den lille nøttefrabrikken (Fredrikstad, Norway) & $100 \mathrm{~g}$ & 6.31 \\
\hline Walnuts (Juglans californica) $\dagger$ & Diamond Foods, Inc. (Stockton, CA, USA) & $200 \mathrm{~g}$ & 44.48 \\
\hline Extra Virgin Olive Oil (Olea europaea)‡ & Ybarra (Toano, Spain) & 0.063 litres & 0.19 \\
\hline Rosemary (Rosmarinus officinalis) $\ddagger$ & Black Boy (Bergen, Norway) & $3 \mathrm{~g}$ & 1.55 \\
\hline Thyme (Thymus vulgaris) $\ddagger$ & Black Boy (Bergen, Norway) & $3 \mathrm{~g}$ & 1.69 \\
\hline Oregano (Origanum vulgare gracile) $\ddagger$ & Black Boy (Bergen, Norway) & $3 \mathrm{~g}$ & 1.90 \\
\hline Total & & & 304.43 \\
\hline
\end{tabular}

* Food items were provided by the Norwegian University of Life Sciences (Ås, Norway).

† Food items were provided as ingredients in bread.

$\ddagger$ Food items were provided once at the start of the intervention period.

seasonal changes in the participants' diet. The present study was conducted according to the guidelines laid down in the Declaration of Helsinki, and all procedures were approved by the regional ethics for medical research committee and all participants gave a written, informed consent before inclusion. The study is registered as 'Oslo antioxidant study' (NCT00520819) at www.clinicaltrials.gov

\section{Compliance, tolerability and registration of undesirable events and diet}

A detailed questionnaire was completed at each weekly follow-up to record compliance, as well as any challenges and difficulties related to the intake of the intervention items.

The questionnaire was designed to record any dietary items that were not consumed during the preceding week, as well as the acceptance of the dietary intervention (i.e. whether the participants found it palatable or not). To ease the completion of the questionnaire, all participants were instructed to bring the remaining food items to the weekly follow-up. Compliance was based on the information obtained from the questionnaires. Individual counselling was given to the participants in the antioxidant-rich diet group by a trained nutritionist to help them consume the provided food items by suggesting recipes and giving practical advice in preparing the food. For those who had problems implementing parts of the intervention diet, food items were exchanged within other antioxidant-rich foods (Table 1).

Undesirable events were recorded at weekly follow-ups by a specific question related to the occurrence of any adverse events. If any events were reported, questions about specific symptoms were asked and recorded in the questionnaire.

Tolerability was evaluated based on the data related to the acceptance of the dietary intervention, as well as reported undesirable events.

Habitual dietary intake, as well as dietary intake during the intervention period, was recorded using a $7 \mathrm{~d}$ food record with a picture book. The $7 \mathrm{~d}$ food record with a picture book used in the present study has been validated using a weighed food record as a reference method, demonstrating that the reported energy and nutrient intake are valid on a group level ${ }^{(19)}$. The food records were completed in the last week of the run-in period (i.e. the week preceding randomisation) and during the last week of the intervention period. Average daily intake of energy and nutrients was computed using the food database AE-07 and KBS software system (KBS, 2008; version 4.9; Oslo, Norway) developed at the Department of Nutrition, University of Oslo, Norway. The food database AE-07 is based on the 2006 edition of the Norwegian food composition table (http://www.norwegianfoodcomp.no). The antioxidant values in $\mathrm{AE}-07$ are based on the comprehensive antioxidant food database developed at the Department of Nutrition, University 
of Oslo ${ }^{(13,14)}$. A total of four participants failed to return their dietary records; thus, data on dietary intake were available for thirty-two participants in each group.

\section{Laboratory analysis}

Overnight, fasting blood samples were collected between 08.00 and 10.00 hours before and after the intervention period. Plasma and serum were prepared from blood samples within $1 \mathrm{~h}$ after sampling, and stored at $-70^{\circ} \mathrm{C}$ until time of analysis unless immediately analysed.

Analysis of antioxidants in plasma. To preserve vitamin C in the plasma, heparin plasma was immediately acidified using an equal volume of $10 \%$ meta-phosphoric acid and stored at $-70^{\circ} \mathrm{C}$ until analysis within 3 months. The vitamin $\mathrm{C}$ isoform ascorbic acid was determined by HPLC ${ }^{(20,21)}$. Plasma calibrators quantified against the National Institute of Standards and Technology 970 standardised reference material were used as standards.

For the determination of tocopherols by HPLC, proteins were precipitated by the addition of three volumes of isopropanol followed by centrifugation at $3000 \mathrm{~g}$ at $4^{\circ} \mathrm{C}$ for $15 \mathrm{~min}$. The internal standard tocol was added with the isopropanol. A total of $5 \mu$ l of the clear supernatant was used for the analysis by $\mathrm{HPLC}^{(22)}$. Standards prepared in $1 \%$ bovine serum albumin in PBS were used for quantification.

The carotenoids lutein, zeaxanthin, $\beta$-kryptoxanthin, $\alpha$-carotene, $\beta$-carotene and lycopene were determined in plasma by HPLC. Proteins were precipitated and removed by the addition of a 4.5 volume of isopropanol followed by centrifugation at $3000 \mathrm{~g}$ at $4{ }^{\circ} \mathrm{C}$ for $15 \mathrm{~min}$. The internal standard astaxanthin was added with isopropanol. A total of $25 \mu \mathrm{l}$ of the clear supernatant was used for the analysis. The mobile phases consisted of A (20\% water and 24\% acetone in ethanol) and $\mathrm{B}$ (acetone). The gradient conditions were as follows: from 2 to $100 \%$ mobile phase B within $20 \mathrm{~min}$, followed by $100 \%$ mobile phase B for $15 \mathrm{~min}$. Detection was performed at $453 \mathrm{~nm}$ using a variable wavelength detector. Plasma calibrators quantified against the National Institute of Standards and Technology 968c standardised reference material were used as standards.

Quercetin was analysed by HPLC and electrochemical detection after enzymatic hydrolysis ${ }^{(23)}$. Phenolic acids and enterolactone were analysed by GC-MS after enzymatic hydrolysis ${ }^{(24)}$

Analysis of total antioxidant capacity in plasma. FRAP was determined in plasma and in the extracts of plasma free of uric acid and proteins (modified FRAP) ${ }^{(25)}$. For the preparation of extracts free of uric acid and proteins, $10 \mu$ l uricase $(0 \cdot 1$ units $/ 10 \mu \mathrm{l})$ in Tris buffer $(\mathrm{pH} 8 \cdot 5,400 \mathrm{mmol} / \mathrm{l})$ were added to $60 \mu \mathrm{l}$ plasma. After incubation for $5 \mathrm{~min}$ at room temperature, $120 \mu \mathrm{l}$ ethanol were added to precipitate the proteins. Samples were placed at $4^{\circ} \mathrm{C}$ for $5 \mathrm{~min}$ before centrifugation at $13000 \mathrm{~g}$ at $4^{\circ} \mathrm{C}$ for $5 \mathrm{~min}$. The uric acid- and protein-free supernatants were used for FRAP analysis.

Total peroxyl radical-trapping activity was measured in plasma by a modified version of an assay described elsewhere $^{(26)}$. Briefly, plasma was added to the reaction mixture made up to a $200 \mu \mathrm{l}$ final volume before incubation. The oxidation reaction was initiated by the addition of $2,2^{\prime}$-azobis(2amidinopropane). The decay of fluorescence was monitored every minute for $60 \mathrm{~min}$ (at $495 \mathrm{~nm}$ (excitation) and $570 \mathrm{~nm}$ (emission)) on a fluorescence microplate reader (GENios Standard TECAN Italia, Milano Due, Segrate, Italy). Results are expressed as $\mu \mathrm{M}$-trolox equivalents.

Plasma samples for the oxygen radical absorbance capacity (ORAC) assay were thawed and kept on ice. To isolate the protein-free fraction, plasma proteins were precipitated by the addition of $0.5 \mathrm{M}$-perchloric acid (PCA) to an equal volume of plasma before centrifugation at $13000 \mathrm{~g}$ at $4{ }^{\circ} \mathrm{C}$ for $5 \mathrm{~min}$. Plasma (total) or the protein-free supernatant (PCA precipitated) was used for the ORAC assay, with the oxidation reaction initiated with $2,2^{\prime}$-azobis (2-amidinopropane) dihydrochloride $^{(27)}$. Fluorescence was recorded every $3 \mathrm{~min}$ ( $485 \mathrm{~nm}$ (excitation) and $520 \mathrm{~nm}$ (emission)) with the use of a FLUOstar OPTIMA (BMG LABTECH, Offenburg, Germany). ORAC values were calculated using the differences of areas under the fluorescence decay curves between the blank (phosphate buffer) and a sample (net area). Results are expressed as $\mu \mathrm{mol}$ trolox equivalents/1 plasma.

Total phenolics were analysed by a modified version of a previously described method. Briefly, $50 \mu \mathrm{l}$ plasma were mixed with $150 \mu \mathrm{l}$ ethanol for $2 \mathrm{~min}$, before centrifugation at $3000 \mathrm{~g}$ at $4^{\circ} \mathrm{C}$ for $15 \mathrm{~min}$. A total of $50 \mu \mathrm{l}$ of the clear supernatant was used for the determination of total phenolics using the Folin-Ciocalteau reagent ${ }^{(28)}$. Quercetin prepared in ethanol served as standard solutions, and the results are reported as $\mu \mathrm{M}$-quercetin equivalents.

\section{Clinical parameters associated with tissue damage}

Creatinine kinase, alanine aminotranferase, aspartate aminotransferase, albumin, lactate dehydrogenate and creatinine kinase-isoenzyme MB (CK-MB) band were analysed at the Department of Clinical Chemistry at Oslo University Hospital Ullevål (Oslo, Norway) using a Cobas Integra 400/800 analyser (Roche Diagnostics GmbH, Mannheim, Germany).

\section{Biomarkers associated with endogenous antioxidant defence and oxidative damage}

Glutathione was determined according to the 'homocysteine by HPLC' kit provided by Biorad Laboratories $\mathrm{GmbH}$ (Munchen, Germany). Standard solutions prepared in PBS served as calibrators. Erythrocyte antioxidant enzymes were measured in erythrocytes isolated from whole blood using citrate cell preparation tubes. Lysates of erythrocytes were prepared by the addition of an equal amount of water. These were used for the determination of the antioxidant enzymes such as glutathione reductase, glutathione peroxidase, catalase and superoxide dismutase ${ }^{(29)}$. Glutathione $S$-transferase was determined on a Cobas Mira analyser using a modified version of a previously reported assay ${ }^{(30)}$. Briefly, the erythrocyte lysates were diluted to $1: 3$ in $150 \mathrm{~mm}-\mathrm{KCl}$ containing $2 \mathrm{~mm}-$ EDTA and $0 \cdot 1 \%$ Triton X-100 (pH 7.0). A total of $6 \mu$ lysate was transferred to a reaction mixture containing $484 \mu \mathrm{l}$ of 
$1 \mathrm{~mm}$-glutathione in $100 \mathrm{~mm}$-phosphate buffer and $10 \mu \mathrm{l}$ of 1-chloro-2,4-dinitrobenzene in dimethylsulfoxide. Enzyme activities were calculated relative to the amount of $\mathrm{Hb}$, which was measured by a standard kit and Drabkins reagent (Randox Laboratories Limited, Crumlin, Antrim, UK).

Measurement of DNA damage (strand breaks) by the comet assay was performed in lymphocytes as described previously $^{(31)}$. In addition to DNA strand breaks, oxidised bases were measured; they were converted to breaks by digesting nucleoids in the gel using endonuclease III (which recognises oxidised pyrimidines) and formamidopyrimidine-DNA glycosylase (specific for oxidised purines).

The diacron-reactive oxygen metabolites test was performed according to the information from the manufacturer (Diacron International, Grossetto, Italy).

Liquid chromatography-MS/MS (electrospray ionisation, negative mode) was used for the determination of 8-epi PGF $2 \alpha$ (isoprostanes) in EDTA plasma. Plasma was hydrolysed and acidified, before isolated isoprostanes were washed and concentrated using a C-18 solid-phase extraction column. The eluate was dried, and the residue was dissolved in water-methanol (1:1). A total of $50 \mu \mathrm{l}$ was used for chromatographic analysis. Separation was achieved with the use of two SUPELCOSIL ${ }^{\mathrm{TM}} \mathrm{ABZ}+$ Plus columns connected in series at $22^{\circ} \mathrm{C}$. The mobile phases were (A) acetonitrile-formic acid (100:0·1) and (B) water-formic acid (100:0·1) at a flow rate of $0.35 \mathrm{ml} / \mathrm{min}$. The gradient conditions were as follows: mobile phase A from 35 to $55 \%$ for 18 min followed by $55 \%$ A for $2 \mathrm{~min}$.

\section{Statistical analysis}

Kruskal-Wallis one-way ANOVA was used to evaluate whether baseline values or changes during the intervention period differed between the groups. Where significant results were obtained, Student's $t$ test or the Mann-Whitney test was performed to compare the mean and median values, respectively, between the groups. Data for the participants who did not complete the intervention period were excluded from the statistical analysis.

In the antioxidant-rich diet group, changes during the intervention period were significantly different from changes in the control group for a large number of variables. To assess whether all the tests in combination indicate an intervention effect, we have used the non-parametric combination methodology as described by Pesarin ${ }^{(32)}$. This method describes how to combine the $P$ value of individual permutation tests into a single test, comparing the antioxidant-rich diet and the control group using Fisher's combination method.

All statistical analyses were performed using SPSS version 14.0 (SPSS Inc., Chicago, IL, USA). A $P$ value of 0.050 or below was considered statistically significant.

\section{Results}

Of the 137 individuals responding to the advertisement in a local newspaper, 118 were found to be potentially eligible and screened. A total of 102 participants were included and of these, 100 completed the study (thirty-three in the antioxidant-rich diet group, thirty-three in the kiwi fruit group and thirty-four in the control group). The remaining two participants did not complete the intervention, one was excluded in the kiwi fruit group due to a non-fatal cardiovascular event and the other participant was excluded in the antioxidant-rich diet group due to lack of compliance. All baseline characteristics (Table 2) were similar for the three groups.

\section{Compliance to the experimental diets}

With minor exceptions, the participants in the antioxidant-rich diet group consumed all food items that were administered. Of the two excluded participants, one dropped out due to lack of acceptance of the intervention items. Acceptance rates of green tea, red cabbage, kale and blueberry jam were approximately $70 \%$, as some of the participants exchanged these food items with juice, blueberries, dark blue grapes and dark chocolate. Compliance for most other foods was approximately $100 \%$.

In the kiwi fruit group, all participants reported to consume the provided kiwi fruits, with only minor deviation.

\section{Tolerability of the experimental diets}

Only mild undesirable effects were reported during the intervention period. In the antioxidant-rich diet group, four participants reported mild gastrointestinal problems presumably related to the intervention, i.e. mild abdominal pains and mild occasional diarrhoea. Of these, three participants reported that these symptoms were experienced only during the first 2 weeks of the intervention period, whereas one participant experienced continued mild gastrointestinal problems during the entire intervention period. In the kiwi fruit group, four participants reported mild gastrointestinal problems, two of these only for the initial 2 weeks of intervention. However, these symptoms were perceived as manageable and all participants completed the intervention.

During the intervention period, four participants in the antioxidant-rich diet group, four participants in the kiwi fruit group and two participants in the control group reported upper respiratory tract symptoms related to the common cold.

\section{Reported intake of energy and other nutrients}

For all three groups, reported habitual dietary intakes at baseline and changes during the intervention period are listed in Table 3. Intakes of total energy increased significantly during the intervention period in both intervention groups when compared with the control group. In the antioxidant-rich diet group, an increase of $19 \%$ in total energy intake was observed. However, no changes in body weight were observed (0.14 (SD 1.73), - 0.20 (SD 3.16) and -0.30 (SD $1.64) \mathrm{kg}$ ) in the control, antioxidant-rich diet and kiwi fruit groups, respectively. Furthermore, intake of fibre increased significantly in both intervention groups. While the increase in the kiwi group corresponded to a $16 \%$ increase from 
Table 2. Baseline descriptives of the study participants (Mean values and ranges)

\begin{tabular}{|c|c|c|c|c|c|c|c|}
\hline \multirow[b]{3}{*}{ Variable } & \multirow{2}{*}{\multicolumn{2}{|c|}{$\frac{\text { Control group (n 34) }}{\text { Baseline }}$}} & \multirow{2}{*}{\multicolumn{2}{|c|}{$\begin{array}{c}\begin{array}{c}\text { Antioxidant-rich diet } \\
\text { group }(n 33)\end{array} \\
\text { Baseline }\end{array}$}} & \multirow{2}{*}{\multicolumn{2}{|c|}{$\frac{\text { Kiwi fruit group (n 33) }}{\text { Baseline }}$}} & \multirow[b]{3}{*}{$P^{*}$} \\
\hline & & & & & & & \\
\hline & Mean & Range & Mean & Range & Mean & Range & \\
\hline Age (years) & 56 & $44-71$ & 57 & $45-74$ & 57 & $45-73$ & 0.770 \\
\hline Weight (kg) & $83 \cdot 7$ & $66 \cdot 2-99 \cdot 8$ & $79 \cdot 3$ & $50 \cdot 7-110$ & $76 \cdot 8$ & $55 \cdot 0-98 \cdot 2$ & $0.021 \dagger$ \\
\hline BMI $\left(\mathrm{kg} / \mathrm{m}^{2}\right)$ & $24 \cdot 8$ & $21 \cdot 6-30 \cdot 4$ & $25 \cdot 7$ & $19 \cdot 4-32 \cdot 0$ & $24 \cdot 7$ & $18 \cdot 8-32 \cdot 2$ & 0.997 \\
\hline Cigarettes (per d) & 15 & $6-35$ & 15 & $5-40$ & 15 & $5-25$ & 0.987 \\
\hline
\end{tabular}

* $P$ values are obtained by comparing baseline means between the groups using the Kruskal-Wallis test.

$\dagger$ Baseline means are significantly different between the kiwi fruit and the control groups $(P<0.05)$.

baseline, a more substantial increase of $76 \%$ was observed in the antioxidant-rich diet group (Table 3).

Minor, but significant, changes in the intakes of carbohydrates and proteins were observed in both intervention groups. Intakes of SFA and PUFA were only slightly altered in the kiwi fruit groups, whereas the intake of SFA decreased by $18 \%$ and the intake of PUFA increased by $46 \%$ in the antioxidant-rich diet group.

\section{Reported intake of dietary antioxidants}

Baseline reported intakes of total antioxidants were about $30 \mathrm{mmol} / \mathrm{d}$ in all groups (Fig. 1 and Table 3). In the antioxidant-rich diet group, the median increase in the intake of dietary antioxidants was $31.4 \mathrm{mmol} / \mathrm{d}$, whereas only minor changes were observed in the kiwi fruit and control groups.

Both the antioxidant-rich diet and kiwi fruit groups significantly increased their intake of vitamin $\mathrm{C}$ compared with the control group. Furthermore, substantial and significant increases in the intakes of $\beta$-carotene and tocopherol were observed in the antioxidant-rich diet group (Table 3 ).

The contribution from different foods and food groups to the intake of total antioxidants in the antioxidant-rich diet group as compared with the control group is illustrated in Fig. 1. In both groups, coffee contributed more than $70 \%$ of total antioxidant intake at baseline. In the antioxidant-rich diet group, fruits and berries, coffee and nuts and seeds contributed about 25,20 and $7 \cdot 0 \mathrm{mmol} / \mathrm{d}$, respectively, whereas food groups such as tea, wine, chocolate and grain products together contributed about $10 \mathrm{mmol} / \mathrm{d}$ during the experimental period.

\section{Safety of the experimental diets}

Safety of the experimental diets was investigated using clinical parameters, as well as biomarkers of oxidative stress. As a measure of potential harmful effects of the diets, several common clinical parameters for tissue damage were measured, including creatinine kinase, creatinine kinase-MB, alanine aminotranferase, aspartate aminotransferase, albumin and lactate dehydrogenate. Baseline values and changes during the intervention are given in Table 4. As a measure of oxidative stress, biomarkers associated with endogenous antioxidant defence and oxidative damage were investigated. Baseline values and changes during the intervention in glutathione, antioxidant enzymes and biomarkers of oxidative damage are listed in Table 5. No effects were observed in biomarkers associated with endogenous antioxidant defence, or in any of the investigated biomarkers of oxidative damage in the antioxidant-rich diet group as compared with the control group. In the kiwi fruit group, the change in $\gamma$-glutamyltransferase was significantly different as compared with the control group. However, the absolute change in the kiwi fruit group was minor, whereas a substantial decrease was observed in the control group.

\section{Plasma concentrations of dietary antioxidants}

At baseline, there were no significant differences between the groups in dietary antioxidants in plasma (Table 6).

Following the antioxidant-rich diet, substantial increases in the median plasma concentrations of lutein, $\alpha$-carotene, $\beta$-carotene, quercetin, vanillic acid, protocatechuic acid, homovanillic acid, 3,4-dihydroxyphenyl acetic acid, gallic acid and $p$-coumaric acid were observed (15-161\% increase from baseline). Additionally, an increase of $8 \%$ in proteinfree ORAC, a measure of total antioxidant activity, was observed. These changes were significantly different when compared with the control group (Table 6). Moreover, a trend towards an increase was observed for the phenolic acid 3-hydroxyphenylacetic acid ( $P=0.053)$.

In the kiwi fruit group, increases that were significantly different from the control group were observed for lutein and modified total peroxyl radical-trapping activity, measurements of total antioxidant capacity. Furthermore, a decrease in $\gamma$-tocopherol was observed in the kiwi fruit group.

\section{Combination statistics}

Because several biomarkers of antioxidant status were altered in the antioxidant-rich diet group, combination statistics, where all individual tests are combined into one global test of the intervention effect, were performed ${ }^{(32)}$. Combination of the individual parameters to one single test shows that there is an intervention effect that is significantly different between the antioxidant-rich diet and control groups. The variables that contributed significantly to the intervention effect, results of the permutation tests and the combined statistics are summarised in Table 7. 
Table 3. Daily intake of energy, micronutrients and antioxidants*, at baseline and changes during the intervention period (Mean values, standard deviations, ranges, medians $\uparrow$ and $95 \%$ confidence intervals)

\begin{tabular}{|c|c|c|c|c|c|c|c|c|c|c|c|c|c|}
\hline \multirow[b]{3}{*}{ Variable } & \multicolumn{4}{|c|}{ Control group (n 32) } & \multicolumn{4}{|c|}{ Antioxidant-rich diet group ( $n$ 32) } & \multicolumn{4}{|c|}{ Kiwi fruit group ( $n$ 32) } & \multirow[b]{3}{*}{$P \ddagger$} \\
\hline & \multicolumn{2}{|c|}{ Baseline } & \multicolumn{2}{|c|}{ Change } & \multicolumn{2}{|c|}{ Baseline } & \multicolumn{2}{|c|}{ Change } & \multicolumn{2}{|c|}{ Baseline } & \multicolumn{2}{|c|}{ Change } & \\
\hline & Mean & Range & Mean & SD & Mean & Range & Mean & SD & Mean & Range & Mean & SD & \\
\hline \multicolumn{14}{|l|}{ Energy and micronutrients } \\
\hline Total energy (kJ) & 9767 & $4945-16780$ & -519 & 2213 & 10382 & $5334-16857$ & $1957 \S$ & 2350 & 10001 & $5225-19638$ & $-18 \cdot 5 \S$ & 1961 & $<0.001$ \\
\hline Protein $(E \%)$ & $16 \cdot 3$ & $12 \cdot 1-22 \cdot 6$ & -0.40 & $2 \cdot 0$ & $16 \cdot 1$ & $11 \cdot 2-21 \cdot 1$ & $-2.8 \S$ & $2 \cdot 7$ & $16 \cdot 6$ & $12 \cdot 9-23 \cdot 5$ & $-1.0 \S$ & 2.53 & 0.001 \\
\hline Total fat $(\mathrm{E} \%)$ & 34.4 & $23 \cdot 7-48.9$ & -0.02 & 4.7 & 34.8 & $25 \cdot 5-53.9$ & 0.9 & $5 \cdot 7$ & $35 \cdot 3$ & $25 \cdot 8-45 \cdot 5$ & -0.35 & 4.50 & 0.671 \\
\hline Carbohydrates (E \%) & $42 \cdot 2$ & $24 \cdot 1-56 \cdot 8$ & -0.9 & $7 \cdot 4$ & $41 \cdot 2$ & $28 \cdot 6-50.9$ & $4.5 \S$ & 4.8 & $40 \cdot 6$ & $31 \cdot 2-57$ & $1.96 \S$ & 4.32 & 0.001 \\
\hline SFA† (E \%) & & & & & & & & & & & & & 0.001 \\
\hline $\begin{array}{l}\text { Median } \\
95 \% \mathrm{Cl}\end{array}$ & $13 \cdot 0$ & $8 \cdot 9-19 \cdot 9$ & \multicolumn{2}{|c|}{$\begin{array}{c}0.15 \\
-0.44,1 \cdot 21\end{array}$} & $13 \cdot 3$ & $9 \cdot 3-19 \cdot 6$ & \multicolumn{2}{|c|}{$\begin{array}{c}-2 \cdot 4 \\
-3 \cdot 3,-1 \cdot 6\end{array}$} & $13 \cdot 8$ & $8 \cdot 7-21 \cdot 9$ & \multicolumn{2}{|c|}{$\begin{array}{c}-0.25 \S \\
-0.80,0.57\end{array}$} & \\
\hline MUFA† (E\%) & & & & & & & & & & & & & 0.771 \\
\hline $\begin{array}{l}\text { Median } \\
95 \% \mathrm{CI}\end{array}$ & 11.5 & $6 \cdot 6-18 \cdot 0$ & \multicolumn{2}{|c|}{$\begin{array}{c}-0.10 \\
-0.68,0.86\end{array}$} & 11.5 & $8 \cdot 2-18 \cdot 7$ & \multicolumn{2}{|c|}{$\begin{array}{c}0.25 \\
-0.33,1.21\end{array}$} & 11.5 & $8 \cdot 2-18 \cdot 0$ & \multicolumn{2}{|c|}{$\begin{array}{c}0.35 \\
-0.73,1.17\end{array}$} & \\
\hline PUFA† (E\%) & & & & & & & & & & & & & $<0.00$ \\
\hline $\begin{array}{l}\text { Median } \\
95 \% \mathrm{Cl}\end{array}$ & $7 \cdot 2$ & $4 \cdot 3-11 \cdot 8$ & \multicolumn{2}{|c|}{$\begin{array}{c}-0.65 \\
-1.10,0.06\end{array}$} & 6.5 & $3 \cdot 7-15 \cdot 9$ & \multicolumn{2}{|c|}{$\begin{array}{c}3.0 \S \\
1.7,3.9\end{array}$} & $7 \cdot 3$ & $3 \cdot 6-10 \cdot 2$ & \multicolumn{2}{|c|}{$\begin{array}{c}-0.15 \S \\
-0.87,0.31\end{array}$} & \\
\hline Fibre $(\mathrm{g})$ & 22.5 & $18 \cdot 9-26 \cdot 0$ & $-2 \cdot 8$ & 6.6 & $20 \cdot 2$ & $18 \cdot 0-22.5$ & $3 \cdot 7 \S$ & 4.00 & 22.9 & $20 \cdot 3-25 \cdot 6$ & $17 \cdot 3 \S$ & $10 \cdot 3$ & $<0.001$ \\
\hline Folate\| $(\mu \mathrm{g})$ & 228 & $94-511$ & -9 & 101 & 242 & $94-567$ & $128 \S$ & 109 & 211 & $75-390$ & $76 \S$ & 62 & $<0.001$ \\
\hline \multicolumn{14}{|l|}{ Antioxidants } \\
\hline Total antioxidants $(\mathrm{mmol})$ & $28 \cdot 6$ & $16 \cdot 0-57.9$ & \multirow{2}{*}{\multicolumn{2}{|c|}{$\begin{array}{c}2 \cdot 9 \\
0.1,5 \cdot 7\end{array}$}} & 29.8 & $6 \cdot 1-80 \cdot 8$ & & & $35 \cdot 0$ & $15 \cdot 0-87 \cdot 5$ & & & $<0.001$ \\
\hline $\begin{array}{l}\text { Median } \\
95 \% \mathrm{Cl}\end{array}$ & & & & & & & \multicolumn{2}{|c|}{$\begin{array}{c}31 \cdot 4 \S \\
25 \cdot 2,35 \cdot 9\end{array}$} & & & \multicolumn{2}{|c|}{$\begin{array}{c}1.2 \S \\
-1.4,3.4\end{array}$} & \\
\hline$\beta$-Carotene\| $(\mu \mathrm{g})$ & 2910 & $644-8174$ & -295 & 2170 & 3403 & $426-18605$ & $737 \S$ & 2849 & 2950 & $158-6225$ & -604 & 1243 & 0.001 \\
\hline Tocopherol|| $(\mu \mathrm{g})$ & 11.5 & $3 \cdot 5-32 \cdot 7$ & -0.4 & 4.8 & $14 \cdot 2$ & $5 \cdot 1-34 \cdot 6$ & $12 \cdot 3 \S$ & $7 \cdot 7$ & $11 \cdot 3$ & $3 \cdot 4-26 \cdot 7$ & 0.37 & 4.2 & $<0.001$ \\
\hline Vitamin C\| (mg) & 101 & $32-188$ & -7 & 50 & 119 & $14-254$ & $241 \S$ & 117 & 90 & $16-159$ & $131 \S$ & 54 & $<0.001$ \\
\hline
\end{tabular}

$E \%$, percentage of energy.

Calculations are based on the $7 \mathrm{~d}$ food record

† Variables are non-normally distributed.

the changes during the intervention period between the groups using the Kruskal-Wallis test.

$\S$ Changes are significantly different compared with changes in the control group.

I Toral antioxidans are

. 


\section{Discussion}

We have demonstrated that male smokers are able to comply with and tolerate a comprehensive diet rich in antioxidants, as well as a simpler dietary change involving kiwi fruit. No potential harmful or pro-oxidative effects were observed, demonstrating the safety of the dietary intervention strategies.

The reported compliance was very good for both intervention strategies, and the majority of the participants were able to comply with the comprehensive antioxidant-rich diet and to the kiwi fruit diet during the 8-week intervention period. In the antioxidant-rich diet group, a few food items were unfamiliar to the participants, such as green tea, red cabbage, kale and blueberry jam. Some of these items were replaced with other foods such as broccoli, blue grapes, blueberries and dark chocolate. Only one participant was excluded due to lack of compliance. Although the participants in the antioxidant-rich diet group increased their intake of fruit and vegetables from 400 to $1550 \mathrm{~g} / \mathrm{d}$ (data not shown), only a few experienced minor undesirable events during the 8-week intervention period. Similarly, very few experienced problems in the kiwi fruit group. A total of eight participants equally divided between the intervention groups experienced mild gastrointestinal problems related to the intervention diet. Of these, three participants in the antioxidant-rich diet group

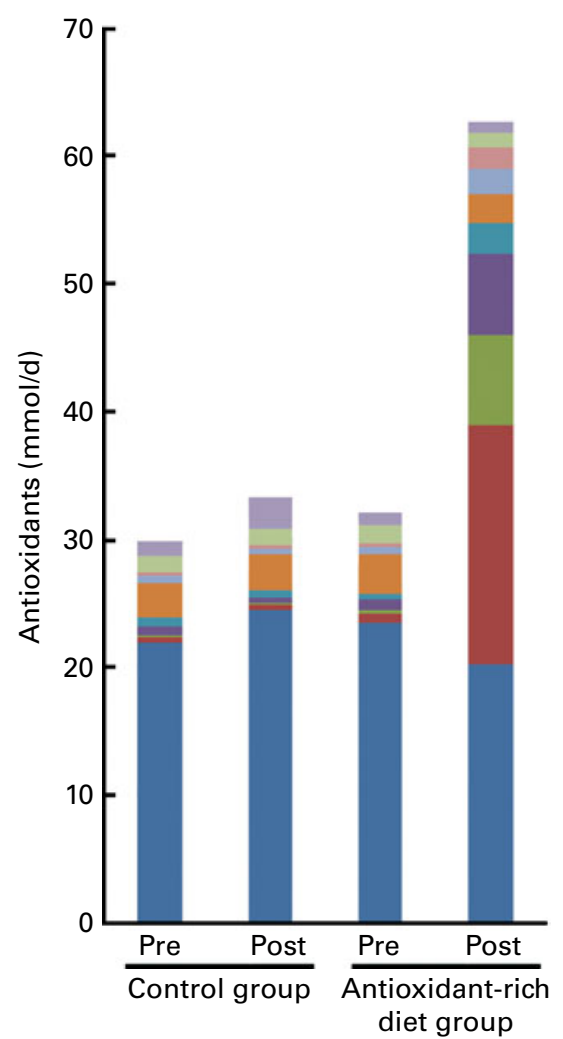

Fig. 1. Total intake of antioxidants in the antioxidant-rich diet group and the control group before and during the intervention. The food group 'grain products' includes bread, breakfast cereals and cakes. The food group 'other foods' includes spices, oils, meat, fish, eggs and dairy products. Intakes of antioxidants are determined using ferric-reducing/antioxidant potential

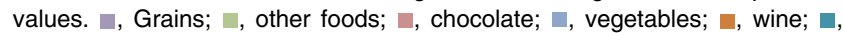
tea; $\mathbf{n}$, fruits and berries; $\mathbf{n}$, nuts and seeds; $\square$, juice; $\mathbf{n}$, coffee.

古

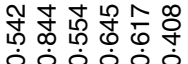

ก ᄂ

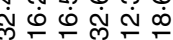

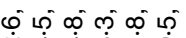
ถุ

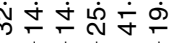

0 $10+\dot{1} \dot{1}$

ำ

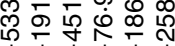
1 1 1 1111

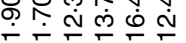


Table 5. Baseline values and changes during the intervention in biomarkers associated with the endogenous antioxidant defence and oxidative damage (Mean values, standard deviations, ranges, medians* and $95 \%$ confidence intervals)

\begin{tabular}{|c|c|c|c|c|c|c|c|c|c|c|c|c|c|}
\hline \multirow[b]{3}{*}{ Variable } & \multicolumn{4}{|c|}{ Control group ( $n$ 34) } & \multicolumn{4}{|c|}{ Antioxidant-rich diet group ( $n$ 33) } & \multicolumn{4}{|c|}{ Kiwi fruit group ( $n 33$ ) } & \multirow[b]{3}{*}{$P \dagger$} \\
\hline & \multicolumn{2}{|c|}{ Baseline } & \multicolumn{2}{|c|}{ Change } & \multicolumn{2}{|c|}{ Baseline } & \multicolumn{2}{|c|}{ Change } & \multicolumn{2}{|c|}{ Baseline } & \multicolumn{2}{|c|}{ Change } & \\
\hline & Mean & Range & Mean & SD & Mean & Range & Mean & SD & Mean & Range & Mean & SD & \\
\hline \multicolumn{14}{|c|}{$\begin{array}{l}\text { Biomarkers associated with } \\
\text { endogenous antioxidant defence }\end{array}$} \\
\hline Glutathione ${ }^{\star}(\mu \mathrm{mol} / \mathrm{l})$ & & & & & & & & & & & & & 0.148 \\
\hline $\begin{array}{l}\text { Median } \\
95 \% \mathrm{Cl}\end{array}$ & 1.53 & $0.70-2.95$ & \multicolumn{2}{|c|}{$\begin{array}{c}-0.0 \\
-0.1,0.2\end{array}$} & 1.45 & $0.58-3.02$ & \multicolumn{2}{|c|}{$\begin{array}{c}-0.03 \\
-0.2,0.3\end{array}$} & 1.61 & $0 \cdot 76-2 \cdot 86$ & \multicolumn{2}{|c|}{$\begin{array}{c}-0.13 \\
-1.0,1 \cdot 6\end{array}$} & \\
\hline $\mathrm{GR}(\mathrm{U} / \mathrm{g} \mathrm{Hb})$ & $9 \cdot 3$ & $7 \cdot 7-12 \cdot 4$ & -0.08 & 0.79 & 8.9 & $7 \cdot 5-11 \cdot 1$ & -0.06 & 0.75 & $9 \cdot 6$ & $7.4-12.5$ & 0.04 & 1.01 & 0.892 \\
\hline GPx (U/g Hb) & $75 \cdot 7$ & $48-115$ & $-1 \cdot 15$ & 8.7 & 71.9 & $9 \cdot 1-103 \cdot 0$ & 1.87 & $16 \cdot 9$ & 78.3 & $49 \cdot 1-109 \cdot 6$ & -0.60 & 11.4 & 0.586 \\
\hline $\mathrm{SOD}(\mathrm{U} / \mathrm{g} \mathrm{Hb})$ & 1159 & $461-1538$ & -70 & 230 & 1112 & $750-1428$ & -19 & 246 & 1115 & $438-1502$ & -33 & 302 & 0.735 \\
\hline CAT $(\mathrm{U} / \mathrm{g} \mathrm{Hb})$ & $12 \cdot 1$ & $8 \cdot 1-14 \cdot 2$ & -0.15 & 0.96 & 11.6 & $8 \cdot 9-14 \cdot 3$ & -0.01 & 0.80 & $12 \cdot 28$ & $9 \cdot 32-15 \cdot 3$ & -0.35 & 1.03 & 0.175 \\
\hline GST (U/g Hb) & $3 \cdot 8$ & $2.5-9 \cdot 0$ & 0.37 & 0.95 & 3.7 & $1 \cdot 6-11 \cdot 3$ & 0.19 & $1 \cdot 10$ & 4.2 & $2.5-10.8$ & -0.1 & 0.8 & 0.736 \\
\hline \multicolumn{14}{|c|}{$\begin{array}{l}\text { Biomarkers associated with oxidative } \\
\text { damage }\end{array}$} \\
\hline DNA strand breaks* $(\mathrm{AU})$ & & & & & & & & & & & & & 0.545 \\
\hline $\begin{array}{l}\text { Median } \\
95 \% \mathrm{Cl}\end{array}$ & 147 & $45-241$ & \multicolumn{2}{|c|}{$\begin{array}{c}-15 \\
-206,114\end{array}$} & 156 & $40-223$ & \multicolumn{2}{|c|}{$\begin{array}{c}-20 \\
-152,102\end{array}$} & 170 & $32-243$ & \multicolumn{2}{|c|}{$\begin{array}{c}-10 \\
-39,4\end{array}$} & \\
\hline Oxidised purines* $(\mathrm{AU})$ & & & & & & & & & & & & & 0.891 \\
\hline $\begin{array}{l}\text { Median } \\
95 \% \mathrm{Cl}\end{array}$ & 182 & $1-237$ & \multicolumn{2}{|c|}{$\begin{array}{c}-9 \\
32,32\end{array}$} & 180 & $92-256$ & \multicolumn{2}{|c|}{$\begin{array}{c}-2 \\
-148,105\end{array}$} & 166 & $66-270$ & \multicolumn{2}{|c|}{$\begin{array}{c}-11 \\
-23,16\end{array}$} & \\
\hline Oxidised pyrimidines* $(A U)$ & & & & & & & \multirow{2}{*}{\multicolumn{2}{|c|}{$\begin{array}{c}-2 \\
-93,109\end{array}$}} & & & \multirow{3}{*}{\multicolumn{2}{|c|}{$\begin{array}{c}-4 \\
-23,23\end{array}$}} & 0.800 \\
\hline $\begin{array}{l}\text { Median } \\
95 \% \mathrm{Cl}\end{array}$ & 115 & $1-217$ & \multicolumn{2}{|c|}{$\begin{array}{c}-4 \\
-135,161\end{array}$} & 114 & $26-206$ & & & 112 & $21-239$ & & & \\
\hline$\gamma-\mathrm{GT}^{*}(\mathrm{U} / \mathrm{I})$ & & & & & & & & & & & & & 0.013 \\
\hline $\begin{array}{l}\text { Median } \\
95 \% \mathrm{Cl}\end{array}$ & $26 \cdot 0$ & $11 \cdot 0-142 \cdot 0$ & \multicolumn{2}{|c|}{$\begin{array}{c}-4 \cdot 6 \\
-8 \cdot 3,-1\end{array}$} & $34 \cdot 0$ & $14 \cdot 0-201 \cdot 0$ & \multicolumn{2}{|c|}{$\begin{array}{c}-0.4 \\
-10 \cdot 0,9 \cdot 2\end{array}$} & 26 & $14-146$ & \multicolumn{2}{|c|}{$\begin{array}{c}0.0 \ddagger \\
-8,35\end{array}$} & \\
\hline D-ROM (Carr U) & 217 & $169-261$ & $7 \cdot 3$ & 21 & 221 & $122-286$ & 7.9 & 27 & 213 & $153-306$ & -2 & 22 & 0.159 \\
\hline Isoprostanes (pg/ml) & $51 \cdot 7$ & $30 \cdot 3-109$ & $17 \cdot 3$ & 33.0 & 51.9 & $27 \cdot 1-98 \cdot 7$ & $17 \cdot 1$ & 30.4 & 48.3 & $31.5-78.3$ & $24 \cdot 0$ & $25 \cdot 2$ & 0.239 \\
\hline
\end{tabular}

GR, glutathione reductase; GPx, glutathione peroxidase; SOD, superoxide dismutase; CAT, catalase; GST, glutathione S-transferase; AU, arbitrary units; $\gamma$-GT, $\gamma$-glutamyltransferase; D-ROM, diacron-reactive oxygen metabolite. * Variables are non-normally distributed.

$\dagger P$ values are obtained by comparing the changes during the intervention period between the groups using the Kruskal-Wallis test.

‡ Changes are significantly different compared with changes in the control group $(P<0 \cdot 05)$. 
WS British Journal of Nutrition

Table 6. Baseline values and changes during the intervention in dietary antioxidant compounds measured in plasma

(Mean values, standard deviations, ranges, medians ${ }^{*}$ and $95 \%$ confidence intervals)

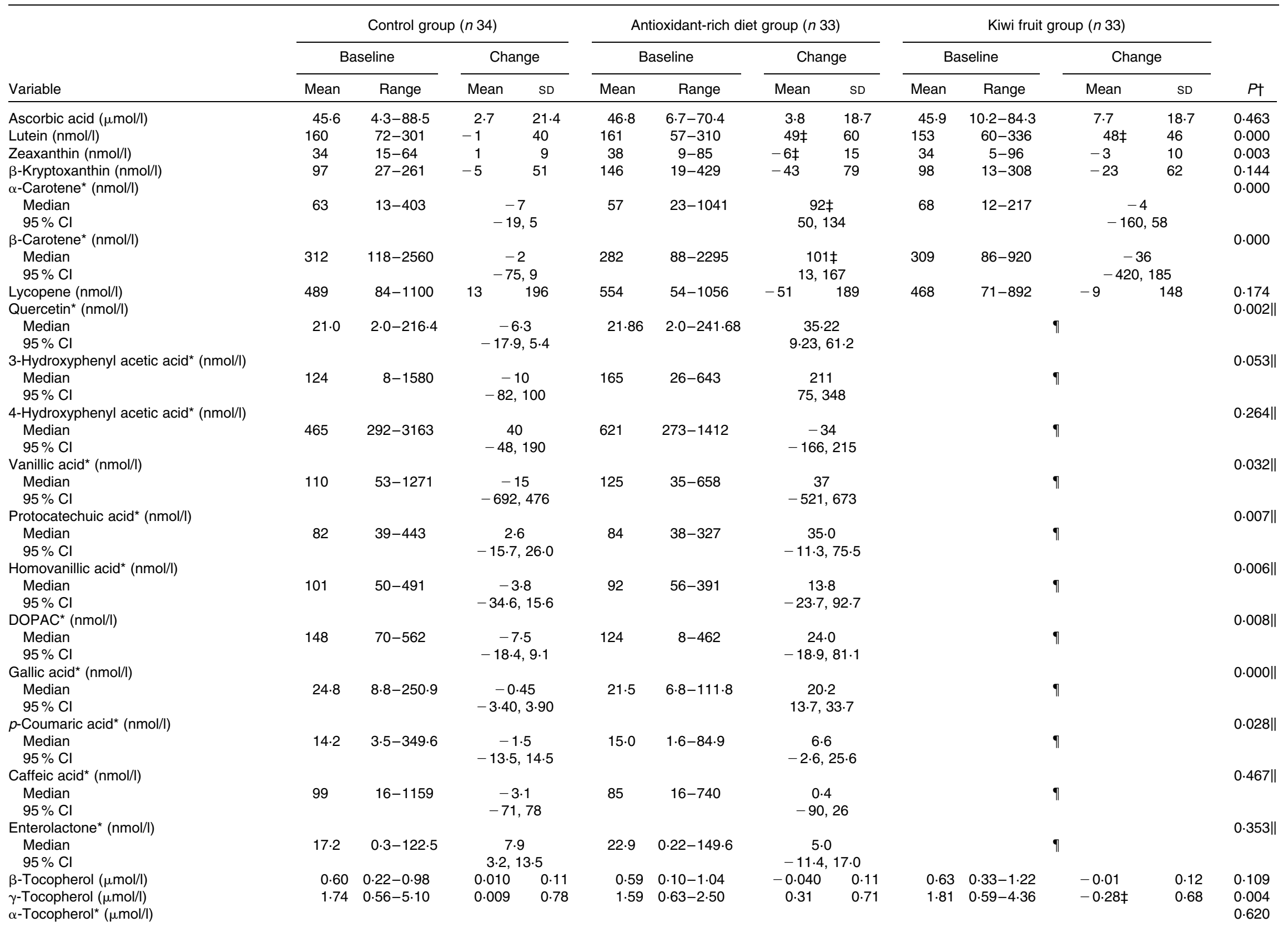




\begin{tabular}{|c|c|c|c|c|c|c|c|c|c|c|c|c|c|}
\hline \multirow[b]{3}{*}{ Variable } & \multicolumn{4}{|c|}{ Control group ( $n 34)$} & \multicolumn{4}{|c|}{ Antioxidant-rich diet group ( $n$ 33) } & \multicolumn{4}{|c|}{ Kiwi fruit group ( $n$ 33) } & \multirow[b]{3}{*}{$P \dagger$} \\
\hline & \multicolumn{2}{|c|}{ Baseline } & \multicolumn{2}{|c|}{ Change } & \multicolumn{2}{|c|}{ Baseline } & \multicolumn{2}{|c|}{ Change } & \multicolumn{2}{|c|}{ Baseline } & \multicolumn{2}{|c|}{ Change } & \\
\hline & Mean & Range & Mean & SD & Mean & Range & Mean & SD & Mean & Range & Mean & SD & \\
\hline 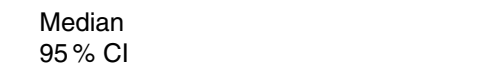 & $27 \cdot 4$ & $18 \cdot 9-41 \cdot 5$ & \multicolumn{2}{|c|}{$\begin{array}{c}9.5 \\
-0.01,0.1\end{array}$} & $26 \cdot 5$ & $15 \cdot 6-41 \cdot 6$ & \multicolumn{2}{|c|}{$\begin{array}{c}2.0 \\
-0.01,0.03\end{array}$} & $25 \cdot 1$ & $16 \cdot 4-47 \cdot 2$ & \multicolumn{2}{|c|}{$\begin{array}{c}0.12 \\
-1.2,1.5\end{array}$} & \\
\hline \multicolumn{14}{|l|}{ Measurements of total antioxidant activity } \\
\hline $\begin{array}{l}\text { FRAP }(\mu \mathrm{mol} / \mathrm{l}) \\
\text { Modified FRAP }(\mu \mathrm{mol} / \mathrm{l})\end{array}$ & 1235 & $865-1577$ & 79 & 165 & 1218 & $910-1579$ & 67 & 145 & 1262 & $994-1698$ & 62 & 177 & $\begin{array}{l}0.996 \\
0.046\end{array}$ \\
\hline $\begin{array}{l}\text { Median } \\
95 \% \mathrm{Cl}\end{array}$ & 304 & $209-430$ & \multicolumn{2}{|c|}{$\begin{array}{c}-9 \\
-19,16\end{array}$} & 312 & $190-451$ & \multicolumn{2}{|c|}{$\begin{array}{c}-2 \\
-86,62\end{array}$} & 302 & $200-464$ & \multicolumn{2}{|c|}{$\begin{array}{l}15 \ddagger \\
-99,167\end{array}$} & \\
\hline ORAC ( $\mu \mathrm{mol} \mathrm{TE} / \mathrm{ml})$ & $14 \cdot 8$ & $11 \cdot 7-18 \cdot 2$ & 0.405 & 2.01 & $15 \cdot 3$ & $11 \cdot 8-19 \cdot 8$ & -0.20 & 2.50 & $15 \cdot 0$ & $11 \cdot 1-20 \cdot 0$ & 0.07 & 1.776 & 0.375 \\
\hline ORAC, protein free $(\mu \mathrm{mol} \mathrm{TE} / \mathrm{ml})$ & 1.19 & $0.83-2.53$ & -0.02 & 0.22 & 1.09 & $0.73-1.40$ & $0.08 \ddagger$ & 0.14 & 1.07 & $0.80-1.44$ & 0.04 & 0.16 & 0.027 \\
\hline $\begin{array}{l}\text { TRAP }^{\star}(\mu \mathrm{mol} \mathrm{TE} / \mathrm{ml}) \\
\text { Median } \\
95 \% \mathrm{Cl}\end{array}$ & 1021 & $843-1320$ & \multicolumn{2}{|c|}{$\begin{array}{c}-36 \\
-125,53\end{array}$} & 1064 & $818-1395$ & \multicolumn{2}{|c|}{$\begin{array}{c}-53 \\
461,4\end{array}$} & 1026 & $831-1332$ & \multicolumn{2}{|c|}{$\begin{array}{c}-47 \\
-134,38\end{array}$} & 0.821 \\
\hline $\begin{array}{l}\text { TRAP }{ }^{\star} \text {, protein free }(\mu \mathrm{mol} \mathrm{TE} / \mathrm{ml}) \\
\text { Median } \\
95 \% \mathrm{Cl}\end{array}$ & 787 & $630-1057$ & \multicolumn{2}{|c|}{$\begin{array}{c}24 \\
-10,57\end{array}$} & 801 & $621-1066$ & \multicolumn{2}{|c|}{$\begin{array}{c}-35 \\
-97,28\end{array}$} & 806 & $84-1084$ & \multicolumn{2}{|c|}{$\begin{array}{c}13 \\
-47,72\end{array}$} & 0.261 \\
\hline $\begin{array}{l}\text { Total phenolics* }(\mu \mathrm{mol} / \mathrm{QE} / \mathrm{ml}) \\
\text { Median } \\
95 \% \mathrm{Cl}\end{array}$ & 317 & $192-436$ & \multicolumn{2}{|c|}{$\begin{array}{l}-6 \\
-9,31\end{array}$} & 330 & $268-404$ & \multicolumn{2}{|c|}{$\begin{array}{c}-8 \\
-21,19\end{array}$} & 315 & $204-424$ & \multicolumn{2}{|c|}{$\begin{array}{c}-1 \\
-81,189\end{array}$} & 0.713 \\
\hline
\end{tabular}

DOPAC, 3,4-dihydroxyphenyl acetic acid; FRAP, ferric-reducing/antioxidant power; ORAC, oxygen radical absorbance capacity; TE, trolox equivalents; TRAP, total peroxyl radical-trapping activity; QE, quercetin equivalents. "Variables are non-normally distributed.

(he changes during the intervention period between the groups using the Kruskal-Wallis test.

₹ Changes are significantly different when compared with changes in the control group $(P<0.05)$.

ann-Whitney $U$ test.

I Phenolic compounds were not analysed in the kiwi fruit group. 
and two participants in the kiwi fruit group reported just temporary discomfort. Those with continuous problems perceived these as manageable and were able to complete the intervention. Due to the low number of participants experiencing adverse events, it is not possible to establish which dietary constituents may have been responsible. The kiwi fruit group was provided with three kiwi fruits/d. Kiwi fruits were selected due to their high antioxidant content, as well as their high content of vitamin C. Furthermore, a few studies have indicated beneficial effects of kiwi fruit consumption $^{(33-35)}$. The amount was chosen based on the previous experience of the tolerability of kiwi fruit consumption over time ${ }^{(34)}$.

We have previously assessed the content of total antioxidants in several thousand dietary plants including fruits, berries, vegetables, cereals, nuts and herbs ${ }^{(14,15,36)}$. These data, as well as previously published data on potential bioactivity ${ }^{(37-44)}$, were used to select plant-based dietary items with a high content of antioxidants for the antioxidant-rich diet (Table 1). Different dietary sources, including juices, berries, fruits, vegetables, nuts, oil, chocolate and spices, were selected to provide a broad range of dietary antioxidants.

The antioxidant-rich foods that were administered provided approximately $300 \mathrm{mmol}$ antioxidants/week, as determined by the FRAP assay. In RCT using supplements, daily dosages of up to $2 \mathrm{~g}$ vitamin $\mathrm{C}(11.4 \mathrm{mmol})$ or $5 \mathrm{~g}$ vitamin $\mathrm{E}(11.6 \mathrm{mmol})$ have been administered ${ }^{(16)}$. Both of these correspond to about $23 \mathrm{mmol}$ each in the FRAP assay. Administration of vitamins $\mathrm{C}$ and $\mathrm{E}$ at these dosages would therefore equal $300 \mathrm{mmol} /$ week, which is similar to the amounts of dietary antioxidants that are provided by the antioxidant-rich foods. At baseline, the daily intake of dietary antioxidants was approximately $30 \mathrm{mmol} / \mathrm{d}$, and coffee contributed to nearly $70 \%$ of the total antioxidant intake (Fig. 1). Following the antioxidant-rich diet, a mean increase of $31 \mathrm{mmol}$ antioxidants/d was observed, corresponding to an increase of $220 \mathrm{mmol} /$

Table 7. Plasma variables significantly contributing to the intervention effect in the antioxidant-rich diet group listed in order of declining $P$ values (from permutation tests)

\begin{tabular}{lr}
\hline Variable & \multicolumn{1}{c}{$P$} \\
\hline$\alpha$-Carotene & $<0.001$ \\
Gallic acid & $<0.001$ \\
Lutein & $<0.001$ \\
Quercetin & 0.001 \\
$\beta$-Carotene & 0.003 \\
Homovanillic acid & 0.008 \\
Zeaxanthin & 0.021 \\
$\beta$-Kryptoxanthin & 0.023 \\
DOPAC & 0.024 \\
3-Hydroxyphenyl acetic acid & 0.048 \\
Lycopene & 0.058 \\
$p$-Coumaric acid & 0.065 \\
$\beta$-Tocopherol & 0.066 \\
Vanillic acid & 0.161 \\
$\gamma$-Tocopherol & 0.222 \\
Combined $P^{*}$ & $<0.001$
\end{tabular}

DOPAC, 3,4-dihydroxyphenyl acetic acid.

* The combined $P$ value is associated with the combination test of an intervention effect between the antioxidant-rich diet group and the control group. week. The main contributors were coffee (34\%), juices (29\%), nuts and seeds (11\%), and fruits and berries (10\%) (Fig. 1). The goal of increasing the intake of dietary antioxidants by $300 \mathrm{mmol} /$ week was not fully achieved by all participants. This observation may be explained by the participants who exchanged parts of their habitual diet with intervention items. Although the total intake of antioxidants increased substantially, the contribution from the habitual intake may have been reduced during the intervention period.

The food items provided in the antioxidant-rich diet provided about $3070 \mathrm{~kJ} / \mathrm{d}$. The participants reduced their reported energy intake from other food sources by only $1120 \mathrm{~kJ} / \mathrm{d}$, causing an average increase of $19 \%$ in energy intake during the intervention period. However, no increase in body weight was observed following the intervention (Table 2), although such an increase in energy intake for 8 weeks theoretically should promote an increase in body weight of about $3 \mathrm{~kg}$. As the present study was not designed to accurately assess total energy intake or expenditure, this apparent effect on body weight needs to be addressed in future studies.

Alternatively, the antioxidant-rich diet provided a number of foods rich in polyphenols, as well as fibre. Data from epidemiological and experimental studies suggest that polyphenol-rich food items may exert beneficial effects on body weight. For instance, it has been proposed that green tea may reduce lipolysis of long-chained TAG, interfere with fat emulsification and inhibit fatty acid synthase activity ${ }^{(45)}$. Moreover, results from epidemiological and clinical studies have suggested that consumption of nuts, independent of their high energy content, may promote weight loss or at least limit weight gain $^{(46,47)}$. Furthermore, the antioxidant-rich diets were rich in fibre, a dietary component that potentially may contribute beneficially in body-weight management and limit weight gain by prolonging postprandial satiety ${ }^{(48,49)}$. Taken together, our data may suggest that a diet rich in antioxidant foods might be beneficial in relation to body-weight regulation. This deserves further investigations.

An important aim of the present study was to investigate the safety of a diet designed to provide dietary antioxidants at levels similar to what previously only have been tested in supplementation studies. As a measure of safety, commonly applied clinical parameters associated with tissue damage, in addition to biomarkers associated with endogenous antioxidant defence and oxidative damage to lipids and DNA, were investigated. No potential harmful or pro-oxidative effects were observed following any of the intervention diets.

In the $\alpha$-Tocopherol, $\beta$-Carotene Cancer Prevention study as well as in the Carotene and Retinol Efficacy Trial, where large doses of $\beta$-carotene were administered to middle-aged male smokers, the authors reported increased incidence of cancer in the lung ${ }^{(10,50)}$. Furthermore, it has been suggested that the increased mortality or morbidity observed in some antioxidant supplementation studies may be related to pro-oxidative effects ${ }^{(12)}$. However, few of the large RCT using antioxidant supplementation have reported data related to specific biomarkers of oxidative damage. A recent review has investigated the relationship between oxidative damage to DNA and antioxidants from dietary sources and 
supplements ${ }^{(51)}$. The authors conclude that intervention with antioxidant-rich foods appears to be more effective than supplementation in lowering the excretion of oxidatively damaged DNA. This conclusion is supported by other intervention studies where intake of dietary antioxidants has mediated potential beneficial effects by decreases in certain measures of oxidative damage ${ }^{(52-58)}$ or induction of endogenous antioxidant defence by increases in plasma glutathione or induction of glutathione peroxidase activity ${ }^{(58-60)}$. To our knowledge, such effects have not been investigated in studies where large doses of antioxidant supplements have been administered.

RCT using supplementation are usually conducted over long periods of time (i.e. years), whereas food intervention studies are conducted over short- to medium-term periods (i.e. weeks to months). Due to the varying time aspects, it may not appear easy to compare the effects on endpoints between such studies. However, pro-oxidative effects may be regarded as an acute condition, which over time may be responsible for disease development by accumulation of potentially harmful products. Thus, pro-oxidative effects measured by intermediate biomarkers of oxidative damage may be compared between acute and chronic studies as a measure of potential health effects and safety of the dietary regimens. Taken together, it may be plausible to suggest that a diet rich in antioxidants does not mediate harmful or prooxidative effects, although the intake of total antioxidants may be similar to that used in RCT using supplements.

In the antioxidant-rich diet group, several antioxidants increased in fasting plasma during the intervention (Table 6). It has been proposed that antioxidant compounds with differing chemical properties may constitute an antioxidant network in the plasma and other compartments ${ }^{(61,62)}$. It is hypothesised that these may play an important role in endogenous protection against oxidative insults. A number of the measured antioxidant compounds (i.e. polyphenols) have a rapid metabolism and elimination ${ }^{(63)}$. Although it was not expected to observe large changes in these compounds using overnight, fasting blood samples, we observed several significant increases. Polyphenolic compounds have been demonstrated to be efficient antioxidants in vitro, and in the circulation, these may interact with other compounds of both lipophilic and hydrophobic nature ${ }^{(62)}$. It has been suggested that their rapid metabolism and elimination may serve as a detoxification pathway for oxidative challenges ${ }^{(62)}$.

Increased concentration of certain antioxidant compounds following a fruit and vegetable-based intervention has been reported $^{(59,64-68)}$, although, to our knowledge, the present study is the first to report increases in such a large number of antioxidant compounds with differing chemical properties following intervention with foods rich in antioxidants. The use of combination statistics confirms that a true intervention effect is observed mainly on these variables.

Although participants in the kiwi fruit group significantly increased their intake of vitamin $\mathrm{C}$, no increase in plasma levels was observed, which is in conflict with data from similar studies $^{(69)}$. However, the lack of effects in our study may be explained by the choice of the study population. It is well established that smokers have a higher turnover of vitamin $\mathrm{C}^{(70)}$, and it is possible that absorbed vitamin $\mathrm{C}$ is rapidly degraded.

We have demonstrated that intake of dietary antioxidants at doses similar to those previously tested in supplementation studies mediates a substantial improvement in plasma antioxidants without promoting harmful or pro-oxidative effects, in a population at an increased risk of CVD. In addition, we present evidence that both diets modulated a number of genes and gene pathways related to stress and defence responses ${ }^{(71)}$

In conclusion, male smokers can comply with a diet abundant in antioxidants and to a kiwi fruit diet for 8 weeks. Only minor and temporary side effects were experienced. We have demonstrated that the antioxidant-rich diet was particularly effective in terms of increasing plasma antioxidants. Although the level of consumed antioxidants in this diet may be compared with that previously tested in RCT using supplements, no potentially harmful or pro-oxidative effects were observed. Future studies are needed to explore the impact of such dietary intervention strategies on the risk of chronic diseases related to oxidative stress.

\section{Acknowledgements}

The following authors declare no potential conflict of interest: A. K., M. Sv., I. S., M.-A. S., N. B., J. S., A. B., I. E., M. Se., S. F. R., G. I. B., M. H. C., S. K. B., M. C. M., L. O. D., A. K. D., K. H., P. L., H. A., A. C., S. T. Conflict of interests: R. B. and C. A. D. had an interest in Bioindex AS and Vitas AS. Bioindex was established by Birkeland Innovation, the Technology transfer office at the University of Oslo, while Vitas was established by Oslo Innovation Centre. The present study was supported by grants from the Throne Holst's Foundation, the Research Council of Norway and the Norwegian Cancer Society. The participants recruited via advertisements and from the Department of Preventive Cardiology, Oslo University Hospital Ulleval are greatly appreciated. Substantial contribution to the study coordination is appreciated by the enthusiastic support of Lisa Flakk at the Department of Preventive Cardiology at Oslo University Hospital Ulleval. The laboratory staff at the Centre for Clinical Heart Research, Department of Cardiology, Oslo University Hospital Ulleval provided invaluable help during the study. Kari Holte, Anne Randi Enget, Magnhild Kverneland, Aud Jørgensen and Vibeke Kegel at the Department of Nutrition and Department of Human Nutrition provided valuable contribution to the sample analysis. We also thank Petter Gjeitanger at the Central Kitchen at the Oslo University Hospital Ulleval and the bakers at Apent Bakeri in Oslo for their contribution to the preparation of the dietary items that were provided during the intervention. R. B. formulated the present hypothesis. A. K., M. Sv., I. S., S. F. R., S. K. B., M. C. M., A. K. D., K. H., P. L., C. A. D., H. A., A. C., S. T. and R. B. contributed to the clinical study design, intervention, sample handling and data collection. A. K., J. S. and P. L. were responsible for the statistical analysis. M.-A. S. and M. Sv. were responsible for the participants and their follow-up, as well as administration of the intervention items during the study. A. K., N. B. and A. B. 
were responsible for the analysis of parameters related to antioxidant status and oxidative damage. I. E. was responsible for the analysis of polyphenols in the plasma. M. Se. was responsible for the analysis of plasma total peroxyl radical-trapping activity, whereas G. I. B. performed the analysis of plasma ORAC. S. F. R. and K. H. prepared and provided several food items (as specified in the Subjects and methods section). L. O. D. was responsible for the analysis of antioxidant enzymes in erythrocytes. M.-A. S. and C. A. D. were responsible for handling of the data associated with the registration of dietary intake. M. H. C. was responsible for computing intake of the dietary antioxidants. A. K., P. L. and R. B. participated in the interpretation of the data. A. K. was responsible for drafting the manuscript, which was revised and approved by all authors.

\section{References}

1. Ceconi C, Boraso A, Cargnoni A, et al. (2003) Oxidative stress in cardiovascular disease: myth or fact? Arch Biochem Biophys 420, 217-221.

2. Valko M, Leibfritz D, Moncol J, et al. (2007) Free radicals and antioxidants in normal physiological functions and human disease. Int J Biochem Cell Biol 39, 44-84.

3. Klaunig JE \& Kamendulis LM (2004) The role of oxidative stress in carcinogenesis. Annu Rev Pharmacol Toxicol 44, 239-267.

4. Hak AE, Ma J, Powell CB, et al. (2004) Prospective study of plasma carotenoids and tocopherols in relation to risk of ischemic stroke. Stroke 35, 1584-1588.

5. Sato R, Helzlsouer KJ, Alberg AJ, et al. (2002) Prospective study of carotenoids, tocopherols, and retinoid concentrations and the risk of breast cancer. Cancer Epidemiol Biomarkers Prev 11, 451-457.

6. Sesso HD, Buring JE, Norkus EP, et al. (2004) Plasma lycopene, other carotenoids, and retinol and the risk of cardiovascular disease in women. Am J Clin Nutr 79, 47-53.

7. Holt EM, Steffen LM, Moran A, et al. (2009) Fruit and vegetable consumption and its relation to markers of inflammation and oxidative stress in adolescents. J Am Diet Assoc 109, 414-421.

8. Mahdavi R, Faramarzi E, Seyedrezazadeh E, et al. (2009) Evaluation of oxidative stress, antioxidant status and serum vitamin C levels in cancer patients. Biol Trace Elem Res 130, $1-6$.

9. American Institute of Cancer Research/World Cancer Research Fund (2007) Food, Nutrition, Physical Activity and the Prevention of Cancer: A Global Perspective, vol. 2. Washington, DC: American Institute of Cancer Research/ World Cancer Research Fund.

10. The Alpha-Tocopherol, Beta Carotene Cancer Prevention Study Group (1994) The effect of vitamin E and beta carotene on the incidence of lung cancer and other cancers in male smokers. N Engl J Med 330, 1029-1035.

11. Omenn GS, Goodman GE, Thornquist MD, et al. (1996) Effects of a combination of beta carotene and vitamin A on lung cancer and cardiovascular disease. N Engl J Med 334, $1150-1155$.

12. Bjelakovic G, Nikolova D, Gluud LL, et al. (2007) Mortality in randomized trials of antioxidant supplements for primary and secondary prevention: systematic review and metaanalysis. JAMA 297, 842-857.
13. Carlsen MH, Halvorsen BL, Holte K, et al. (2010) The total antioxidant content of more than 3100 foods, beverages, spices, herbs and supplements used worldwide. Nutr J9, 1-11.

14. Halvorsen BL, Holte K, Myhrstad MC, et al. (2002) A systematic screening of total antioxidants in dietary plants. $J$ Nutr 132, 461-471.

15. Halvorsen BL, Carlsen MH, Phillips KM, et al. (2006) Content of redox-active compounds (ie, antioxidants) in foods consumed in the United States. Am J Clin Nutr 84, 95-135.

16. Bjelakovic G, Nikolova D, Gluud LL, et al. (2008) Antioxidant supplements for prevention of mortality in healthy participants and patients with various diseases. Cochrane Database of Systematic Reviews, issue 2, CD007176.

17. Brevik A, Andersen LF, Karlsen A, et al. (2004) Six carotenoids in plasma used to assess recommended intake of fruits and vegetables in a controlled feeding study. Eur $J$ Clin Nutr 58, 1166-1173.

18. Erlund I, Freese R, Marniemi J, et al. (2006) Bioavailability of quercetin from berries and the diet. Nutr Cancer 54, 13-17.

19. Lillegaard IT \& Andersen LF (2005) Validation of a pre-coded food diary with energy expenditure, comparison of underreporters $v$. acceptable reporters. Br J Nutr 94, 998-1003.

20. Karlsen A, Blomhoff $\mathrm{R}$ \& Gundersen TE (2005) Highthroughput analysis of vitamin $\mathrm{C}$ in human plasma with the use of HPLC with monolithic column and UV-detection. J Chromatogr B Analyt Technol Biomed Life Sci 824, $132-138$.

21. Karlsen A, Blomhoff R \& Gundersen TE (2007) Stability of whole blood and plasma ascorbic acid. Eur J Clin Nutr 10, 1233-1236.

22. Richheimer S, Kent M \& Bernart M (1994) Reversed-phase high-performance liquid chromatographic method using a pentafluorophenyl bonded phase for analysis of tocopherols. J Chrom A 677, 75-80.

23. Erlund I, Alfthan G, Siren H, et al. (1999) Validated method for the quantitation of quercetin from human plasma using high-performance liquid chromatography with electrochemical detection. J Chromatogr B Biomed Sci Appl 727, 179-189.

24. Kilkkinen A, Erlund I, Virtanen MJ, et al. (2006) Serum enterolactone concentration and the risk of coronary heart disease in a case-cohort study of Finnish male smokers. Am J Epidemiol 163, 687-693.

25. Benzie IF \& Strain JJ (1999) Ferric reducing/antioxidant power assay: direct measure of total antioxidant activity of biological fluids and modified version for simultaneous measurement of total antioxidant power and ascorbic acid concentration. Methods Enzymol 299, 15-27.

26. Serafini M, Bugianesi R, Salucci M, et al. (2002) Effect of acute ingestion of fresh and stored lettuce (Lactuca sativa) on plasma total antioxidant capacity and antioxidant levels in human subjects. Br J Nutr 88, 615-623.

27. Davalos A, Gomez-Cordoves C \& Bartolome B (2004) Extending applicability of the oxygen radical absorbance capacity (ORAC-fluorescein) assay. J Agric Food Chem 52, 48-54.

28. Maskarinec G, Chan CL, Meng L, et al. (1999) Exploring the feasibility and effects of a high-fruit and -vegetable diet in healthy women. Cancer Epidemiol Biomarkers Prev 8, 919-924.

29. Young JF, Dragstedt LO, Haraldsdottir J, et al. (2002) Green tea extract only affects markers of oxidative status postprandially: lasting antioxidant effect of flavonoid-free diet. $\mathrm{Br} \mathrm{J}$ Nutr 87, 343-355.

30. Habig WH, Pabst MJ \& Jakoby WB (1974) Glutathione $S$-transferases. The first enzymatic step in mercapturic acid formation. J Biol Chem 249, 7130-7139. 
31. Singh NP, McCoy MT, Tice RR, et al. (1988) A simple technique for quantitation of low levels of DNA damage in individual cells. Exp Cell Res 175, 184-191.

32. Pesarin F (2001) Multivariate Permutation Tests. New York: John Wiley and Sons.

33. Collins BH, Horska A, Hotten PM, et al. (2001) Kiwifruit protects against oxidative DNA damage in human cells and in vitro. Nutr Cancer 39, 148-153.

34. Duttaroy AK \& Jorgensen A (2004) Effects of kiwi fruit consumption on platelet aggregation and plasma lipids in healthy human volunteers. Platelets 15, 287-292.

35. Chang WH \& Liu JF (2009) Effects of kiwifruit consumption on serum lipid profiles and antioxidative status in hyperlipidemic subjects. Int J Food Sci Nutr 60, 709-716.

36. Dragland S, Senoo H, Wake K, et al. (2003) Several culinary and medicinal herbs are important sources of dietary antioxidants. J Nutr 133, 1286-1290.

37. Battino M, Beekwilder J, Denoyes-Rothan B, et al. (2009) Bioactive compounds in berries relevant to human health. Nutr Rev 67, S145-S150.

38. Seeram NP (2008) Berry fruits for cancer prevention: current status and future prospects. J Agric Food Chem 56, 630-635.

39. Vauzour D, Vafeidou K, Rendeiro C, et al. (2010) The inhibitory effects of berry-derived flavonoids against neurodegenerative processes. J Berry Res 1, 45-52.

40. Dohadwala MM \& Vita JA (2009) Grapes and cardiovascular disease. J Nutr 139, 1788S-1793S.

41. Karlsen A, Paur I, Bohn SK, et al. (2010) Bilberry juice modulates plasma concentration of NF-kappaB related inflammatory markers in subjects at increased risk of CVD. Eur $J$ Nutr 49, 345-355.

42. Ried K, Sullivan T, Fakler P, et al. (2010) Does chocolate reduce blood pressure? A meta-analysis. BMC Med $\mathbf{8}, 39-49$.

43. Sirtori CR, Galli C, Anderson JW, et al. (2009) Functional foods for dyslipidaemia and cardiovascular risk prevention. Nutr Res Rev 22, 244-261.

44. Willcox JK, Catignani GL \& Lazarus S (2003) Tomatoes and cardiovascular health. Crit Rev Food Sci Nutr 43, 1-18.

45. Cabrera C, Artacho R \& Gimenez R (2006) Beneficial effects of green tea - a review. J Am Coll Nutr 25, 79-99.

46. Coates AM \& Howe PR (2007) Edible nuts and metabolic health. Curr Opin Lipidol 18, 25-30.

47. Sabate J (2003) Nut consumption and body weight. Am J Clin Nutr 78, 647S-650S.

48. Anderson JW, Baird P, Davis RH Jr, et al. (2009) Health benefits of dietary fiber. Nutr Rev 67, 188-205.

49. Astrup A, Kristensen M, Gregersen NT, et al. (2010) Can bioactive foods affect obesity? Ann N Y Acad Sci 1190, 25-41.

50. Omenn GS, Goodman GE, Thornquist MD, et al. (1996) Risk factors for lung cancer and for intervention effects in CARET, the Beta-Carotene and Retinol Efficacy Trial. J Natl Cancer Inst 88, 1550-1559.

51. Moller P \& Loft S (2006) Dietary antioxidants and beneficial effect on oxidatively damaged DNA. Free Radic Biol Med 41, 388-415.

52. Bub A, Watzl B, Abrahamse L, et al. (2000) Moderate intervention with carotenoid-rich vegetable products reduces lipid peroxidation in men. $J$ Nutr 130, 2200-2206.

53. Lean ME, Noroozi M, Kelly I, et al. (1999) Dietary flavonols protect diabetic human lymphocytes against oxidative damage to DNA. Diabetes 48, 176-181.

54. Sanchez-Moreno C, Cano MP, de Ancos B, et al. (2004) Consumption of high-pressurized vegetable soup increases plasma vitamin $\mathrm{C}$ and decreases oxidative stress and inflammatory biomarkers in healthy humans. J Nutr $\mathbf{1 3 4}$, 3021-3025.
55. Thompson HJ, Heimendinger J, Haegele A, et al. (1999) Effect of increased vegetable and fruit consumption on markers of oxidative cellular damage. Carcinogenesis 20 , $2261-2266$.

56. Thompson HJ, Heimendinger J, Gillette C, et al. (2005) In vivo investigation of changes in biomarkers of oxidative stress induced by plant food rich diets. J Agric Food Chem 53, 6126-6132.

57. Thompson HJ, Heimendinger J, Sedlacek S, et al. (2005) 8-Isoprostane F2alpha excretion is reduced in women by increased vegetable and fruit intake. Am J Clin Nutr $\mathbf{8 2}$, $768-776$.

58. Weisel T, Baum M, Eisenbrand G, et al. (2006) An anthocyanin/polyphenolic-rich fruit juice reduces oxidative DNA damage and increases glutathione level in healthy probands. Biotechnol J 1, 388-397.

59. Dragsted LO, Pedersen A, Hermetter A, et al. (2004) The 6-a-day study: effects of fruit and vegetables on markers of oxidative stress and antioxidative defense in healthy nonsmokers. Am J Clin Nutr 79, 1060-1072.

60. Young JF, Nielsen SE, Haraldsdottir J, et al. (1999) Effect of fruit juice intake on urinary quercetin excretion and biomarkers of antioxidative status. Am J Clin Nutr 69, 87-94.

61. Packer L, Weber SU \& Rimbach G (2001) Molecular aspects of alpha-tocotrienol antioxidant action and cell signalling. J Nutr 131, 369S-373S.

62. Yeum KJ, Russell RM, Krinsky NI, et al. (2004) Biomarkers of antioxidant capacity in the hydrophilic and lipophilic compartments of human plasma. Arch Biochem Biophys 430 , $97-103$.

63. Manach C, Scalbert A, Morand C, et al. (2004) Polyphenols: food sources and bioavailability. Am J Clin Nutr 79, $727-747$.

64. Broekmans WM, Klopping-Ketelaars IA, Schuurman CR, et al. (2000) Fruits and vegetables increase plasma carotenoids and vitamins and decrease homocysteine in humans. $J$ Nutr 130, 1578-1583.

65. Chopra M, O'Neill ME, Keogh N, et al. (2000) Influence of increased fruit and vegetable intake on plasma and lipoprotein carotenoids and LDL oxidation in smokers and nonsmokers. Clin Chem 46, 1818-1829.

66. Paterson E, Gordon MH, Niwat C, et al. (2006) Supplementation with fruit and vegetable soups and beverages increases plasma carotenoid concentrations but does not alter markers of oxidative stress or cardiovascular risk factors. J Nutr 136, 2849-2855.

67. Record IR, Dreosti IE \& McInerney JK (2001) Changes in plasma antioxidant status following consumption of diets high or low in fruit and vegetables or following dietary supplementation with an antioxidant mixture. Br J Nutr $\mathbf{8 5}$, 459-464.

68. Roberts WG, Gordon MH \& Walker AF (2003) Effects of enhanced consumption of fruit and vegetables on plasma antioxidant status and oxidative resistance of LDL in smokers supplemented with fish oil. Eur J Clin Nutr 57, 1303-1310.

69. Duttaroy AK \& Jorgensen A (2004) Effects of kiwi fruit consumption on platelet aggregation and plasma lipids in healthy human volunteers. Platelets 15, 287-292.

70. Murata A (1991) Smoking and vitamin C. World Rev Nutr Diet 64, 31-57.

71. Bohn SK, Myhrstad MC, Thoresen M, et al. (2010) Blood cell gene expression associated with cellular stress defense is modulated by antioxidant-rich food in a randomised controlled clinical trial of male smokers. BMC Med $\mathbf{8}, 54$. 